\title{
Use of Carabids for the Post-Market Environmental Monitoring of Genetically Modified Crops
}

\author{
Oxana Skoková Habuštová ${ }^{1, *}$, Zdeňka Svobodová ${ }^{1}$, L'udovít Cagáň ${ }^{2}$ and František Sehnal ${ }^{1,3}$ \\ 1 Institute of Entomology, Biology Centre CAS, Branišovská 31, 37005 České Budějovice, Czech Republic; \\ svobodova@entu.cas.cz (Z.S.); frantisek.sehnal@bc.cas.cz (F.S.) \\ 2 Department of Plant Protection, Faculty of Agrobiology and Food Resources, Slovak Agricultural University, \\ Tr. A. Hlinku 2, 94976 Nitra, Slovakia; ludovit.cagan@gmail.com \\ 3 Faculty of Science, University of South Bohemia in České Budějovice, Branišovská 31, \\ 37005 České Budějovice, Czech Republic \\ * Correspondence: habustova@entu.cas.cz; Tel.: +420-38-777-5252
}

Academic Editors: Juan Ferré and Baltasar Escriche

Received: 4 January 2017; Accepted: 27 March 2017; Published: 29 March 2017

\begin{abstract}
Post-market environmental monitoring (PMEM) of genetically modified (GM) crops is required by EU legislation and has been a subject of debate for many years; however, no consensus on the methodology to be used has been reached. We explored the suitability of carabid beetles as surrogates for the detection of unintended effects of GM crops in general PMEM surveillance. Our study combines data on carabid communities from five maize field trials in Central Europe. Altogether, 86 species and 58,304 individuals were collected. Modeling based on the gradual elimination of the least abundant species, or of the fewest categories of functional traits, showed that a trait-based analysis of the most common species may be suitable for PMEM. Species represented by fewer than 230 individuals (all localities combined) should be excluded and species with an abundance higher than 600 should be preserved for statistical analyses. Sixteen species, representing 15 categories of functional traits fulfill these criteria, are typical dominant inhabitants of agroecocoenoses in Central Europe, are easy to determine, and their functional classification is well known. The effect of sampling year is negligible when at least four samples are collected during maize development beginning from 1 April. The recommended methodology fulfills PMEM requirements, including applicability to large-scale use. However, suggested thresholds of carabid comparability should be verified before definitive conclusions are drawn.
\end{abstract}

Keywords: Carabidae; surrogate; post-market environmental monitoring; PMEM; risk assessment; GM maize; functional trait

\section{Introduction}

Although genetically modified (GM) crops are generally considered safe for non-target arthropods [1], there are still uncertainties regarding the long-term effects caused by the accumulation of miniscule changes in the agroecosystem. Science-based post-market environmental monitoring (PMEM) is therefore required for GM crops by EU legislation (Directive 2001/18/EC, [2,3]). PMEM aims to identify risks that did not become evident during the pre-market risk assessment. Consequently, PMEM results are expected to provide a basis for subsequent regulatory decisions, including the prolongation and modification of the monitoring plans. The detection of adverse changes in the environment may trigger additional research that could eventually lead to the withdrawal of approval for GM crops [4].

There has been much discussion about the PMEM of GM crops, but a general PMEM plan accepted by regulators, scientists, and the agricultural biotech industry is still lacking [5]. PMEMs are a legal 
requirement, and consist of two conceptually different components: (a) case-specific monitoring; and (b) general surveillance (GS) [6], which is the subject of this paper. GS has an unspecified nature. It is part of an inherent challenge for PMEM, because the currently applied GS methodology may not be sensitive enough [7]. The collection of empirical data must be improved and proper baselines of GM-independent insect fluctuations must be established. Since it is impossible to monitor all components of the ecosystems, the selection of surrogate species representing valid entities of the environment is of primary importance.

Five reports [8-12] have proposed that generalist natural enemies are suitable surrogates for the GS component of PMEM. The carabids (Coleoptera: Carabidae) are particularly appropriate because they are species rich, abundant, and functionally diversified in arable habitats all over world [13]. More than 600 species have been recorded in Central Europe [14] and keys for species identification are available. With respect to the method of arthropod collection, pitfall trapping of carabids has a higher capacity to detect differences than the visual monitoring used for the plant-dwelling arthropods [8,9]. Carabids have been considered as bioindicators of the environmental impact of agricultural practices [13,15-19], including the cultivation of GM crops [9,20,21]. Carabids living in fields planted with GM crops are directly and/or indirectly exposed to the products of transgenes [20], depending on their feeding behavior, which ranges from obligate phytophagy to obligate zoophagy, with most granivorous species belonging somewhere in the middle of this continuum [22-24].

Carabids play an important role in agroecosystems by contributing to the elimination of a wide variety of weed seeds [25-27] and pest insects [28]. They tend to have one generation per year. Some reproduce during spring and complete their development in winter; others breed in autumn and hibernate mainly as larvae. Adults of many species reproduce in spring, aestivate in summer, and reproduce again in the autumn [13]. The body size, habitat, and humidity affinities affect life history parameters and ecological interactions of every species [29]. Functional classification of carabids facilitates the assessment of their roles and their occurrence in agroecosystems [30].

Our study evaluated carabids with respect to body size, habitat and humidity affinities, breeding period, and food specialization. This approach requires identification and counting of captured species, and then choice of indicator species that represent crucial functional traits and are sufficiently widespread for statistical analyses [18]. Profound changes in the representation of functional traits alter the role of carabids in the ecosystem and may have considerable environmental consequences. Simple counts of captured beetles do not disclose these environmental impacts because species with different or unknown traits are mixed up [17].

The importance of species-based analysis is supported by the database of the non-target arthropods species proposed for the environmental risk assessment of GM crops in the EU [31]. Several authors have recommended functional analysis for the comparison of insect communities [32-34]. In our analysis of both quantitative and qualitative changes of the carabid community, we combined data on species abundance with information on their functional traits. In this paper, we demonstrate that combining the population size assessment with analyses of functional traits generates a robust and testable method for the comparison of carabid communities.

Since the only GM crop approved for commercial cultivation in the EU is the lepidopteran-resistant maize MON 810, which is grown in five European countries including the Czech Republic and Slovakia [35], we concentrated on carabid communities in maize fields to study the size of the data (how many species, individuals) to be used in GS protocols in the framework of PMEM. Several kinds of maize cultivars, including three GM cultivars, were grown in fields 2-200 km apart. Species diversity and abundance were examined with respect to environmental variables (locality, year, and sampling date) and analyzed in relation to the species and trait categories (body size, habitat and humidity affinities, breeding period, and food specialization) in order to identify optimal conditions for the comparison of communities from different fields and years. 


\section{Results}

\subsection{Characterization and Quantitative Comparison of Carabid Communities}

The sum of catches in all localities totaled 58,304 individuals belonging to 86 species. Within functional traits, the abundance of one category usually prevailed, but the species richness was highest in different categories. This applies to number of individuals and species richness in the size categories B and C, species preferring open biotopes and species with low habitat preferences (eurytopic), and hygrophilous and eurytopic species (humidity affinity). The abundances of spring and autumn breeders were very similar, while the numbers of species differed substantially. A similar situation was found for the carnivorous and omnivorous species (Table 1).

The Simpson dominance and Berger-Parker indices were highest in locality SB3, where $80 \%$ of individuals were identified as Pterostichus melanarius. The second highest index was found in WS with a dominance of Pseudoophonus rufipes (70\%), and the third highest in SB2, where Poecilus cupreus represented $60 \%$ of individuals. The dominance of $P$. rufipes in CB (47\%) and of P. melanarius in SB1 (32\%) was less pronounced. This was reflected in the species evenness, which was highest in SB1 and lowest in SB3 in which species evenness was very similar to WS. The Margalef index detected highest ratio between the number of species and the abundance in SB2 (59 species, 22,015 individuals), followed by SB1 (35 species, 5484 individuals), CB (35 species, 5831 individuals), WS (34 species, 9401 individuals), and SB3 (34 species, 15,573 individuals, Table 2).

The Jaccard and Sørensen-Dice indices showed dissimilarity between communities when all localities were compared. The most similar communities were found in the three geographically closest localities in South Bohemia (Table 3).

\subsection{The Effect of Locality, Year, and Sampling Date on Carabid Communities (All Data Included)}

The location explained $16.3 \%$ and $23.8 \%$ variability in the distribution of carabid species and functional categories, respectively. In the species-based canonical correspondence analysis (CCA), the WS locality explained 10.2\% $(F=169.0, p=0.001), \mathrm{CB} 8.8 \%(F=144.4, p=0.001)$, SB3 3.3\% $(F=50.6$, $p=0.001)$, SB2 $1.9 \%(F=29.1, p=0.001)$, and SB1 1.9\% $(F=29.0, p=0.001)$ variability. The trait-based CCA yielded higher values: SB3 14.9\% $(F=259.8, p=0.001)$, WS 8.9\% $(F=148.0, p=0.001)$, CB 4.9\% $(F=75.3, p=0.001)$, SB2 $4.6 \%(F=71.5, p=0.001)$, and SB1 $2.3 \%(F=33.1, p=0.001)$.

The year explained $1.0 \%(F=14.9, p=0.001)$ and $1.9 \%(F=27.8, p=0.001)$ of variability in the species- and trait-based CCA, respectively. In the species-based CCA, each of the time series S and A explained 3.6\% of variability ( $\mathrm{S}: F=56.3, p=0.001, \mathrm{~A}: F=54.7, p=0.001$ ). The joint analysis of both series proved their close correlation. In the trait-based CCA, the time series $S$ explained $4.3 \%(F=67.1$, $p=0.001)$, and the time series A explained $4.7 \%$ of variability $(F=70.4, p=0.001)$. The joint analysis of both series showed they were correlated, sharing $4.1 \%$ of the variability they explained. Only time series A was used in subsequent modeling.

\subsection{Three Possible Ways of Using Carabids in PMEM}

Variability explained by localities remained relatively stable in the SaS and SaT models (see Section 5.3) until species with abundance lower than 150 and 600 individuals, respectively, were disregarded (Figure 1a). Subsequent step-wise elimination of the more abundant species resulted in a steep increase in explained variability (the difference between variability explained by two adjacent points in the graphs significantly increased, SaS: $F_{1,25}=11.69, p=0.002$, SaT: $F_{1,25}=35.84, p<10^{-5}$ ). Only a small increase in explained variability was observed with the TaT model (Figure 1a). The curve derived from the SaS model intersects the curves of the TaT and SaT models at the points corresponding to species represented by 117 and 229 individuals, respectively, where the variability explained by the SaS model exceeded the variability explained by both the SaT and TaT models. 
Table 1. Quantitative composition of carabids for functional traits in the localities South Bohemia 1 (SB1), 2 (SB2), and 3 (SB3); Central Bohemia (CB); and western Slovakia (WS).

\begin{tabular}{|c|c|c|c|c|c|c|c|c|c|c|c|c|}
\hline \multirow{2}{*}{ Category $^{1}$} & \multicolumn{2}{|c|}{ SB1 } & \multicolumn{2}{|c|}{ SB2 } & \multicolumn{2}{|c|}{ SB3 } & \multicolumn{2}{|c|}{ CВ } & \multicolumn{2}{|c|}{ WS } & \multicolumn{2}{|c|}{ Total } \\
\hline & Individuals & Species & Individuals & Species & Individuals & Species & Individuals & Species & Individuals & Species & Individuals (\%) & Species $(\%)$ \\
\hline \multicolumn{13}{|l|}{ Body size } \\
\hline A & 36 & 1 & 14 & 3 & 2 & 1 & 0 & 0 & 3 & 2 & $55(0.1)$ & $4(5)$ \\
\hline B & 3692 & 8 & 18,349 & 10 & 14,728 & 10 & 2274 & 7 & 7214 & 13 & $46,257(79)$ & $19(22)$ \\
\hline $\mathrm{D}$ & 1300 & 9 & 992 & 12 & 434 & 8 & 456 & 10 & 419 & 7 & $3601(6)$ & $19(22)$ \\
\hline \multicolumn{13}{|l|}{ Habitat affinity } \\
\hline Silvicolous & 59 & 6 & 635 & 15 & 130 & 7 & 66 & 3 & 4 & 7 & $894(2)$ & $19(22)$ \\
\hline Open biotopes & 2673 & 16 & 4861 & 30 & 1437 & 17 & 4302 & 22 & 9009 & 23 & $22,282(38)$ & $44(51)$ \\
\hline Eurytopic & 2752 & 13 & 16,519 & 14 & 14,006 & 10 & 1463 & 10 & 388 & 7 & $35,128(60)$ & $23(27)$ \\
\hline \multicolumn{13}{|l|}{ Humidity affinity } \\
\hline Hygrophilous & 329 & 15 & 2563 & 24 & 404 & 16 & 133 & 11 & 1417 & 8 & $4846(8)$ & $34(40)$ \\
\hline Mesophilous & 2038 & 6 & 3163 & 11 & 12,855 & 6 & 1161 & 4 & 275 & 6 & $19,492(33)$ & 15 (17) \\
\hline Eurytopic & 2288 & 10 & 15,622 & 14 & 1834 & 9 & 3489 & 10 & 6935 & 8 & $30,168(52)$ & $17(20)$ \\
\hline Xerophilous & 829 & 4 & 667 & 10 & 480 & 3 & 1048 & 10 & 774 & 12 & $3798(7)$ & $20(23)$ \\
\hline \multicolumn{13}{|l|}{ Breeding period } \\
\hline Spring & 2340 & 23 & 17,356 & 42 & 2080 & 24 & 3490 & 25 & 1997 & 19 & $27,263(47)$ & $61(71)$ \\
\hline Summer & 141 & 3 & 512 & 6 & 129 & 3 & 241 & 6 & 609 & 4 & $1632(3)$ & $8(9)$ \\
\hline Autumn & 3242 & 14 & 5146 & 21 & 13,610 & 11 & 2434 & 12 & 7232 & 16 & $31,664(54)$ & $29(34)$ \\
\hline \multicolumn{13}{|l|}{ Food specialization } \\
\hline Carnivorous & 4258 & 24 & 7068 & 35 & 13,829 & 24 & 2322 & 20 & 2418 & 21 & $29,895(51)$ & $55(64)$ \\
\hline Granivorous & 0 & 0 & 2 & 1 & 1 & 1 & 1 & 1 & 0 & 0 & $4(0.007)$ & $2(2)$ \\
\hline
\end{tabular}


Table 2. Mean $( \pm \mathrm{SE})$ indices of carabid diversity in the examined localities per year.

\begin{tabular}{cccccc}
\hline Locality & $\begin{array}{c}\text { No. of } \\
\text { Tested Years }\end{array}$ & $\begin{array}{c}\text { Simpson } \\
\text { Dominance Index (D) }\end{array}$ & $\begin{array}{c}\text { Berger-Parker } \\
\text { Index (D) }\end{array}$ & $\begin{array}{c}\text { Species } \\
\text { Evenness (E) }\end{array}$ & $\begin{array}{c}\text { Margalef } \\
\text { Index (DMg) }\end{array}$ \\
\hline SB1 & 1 & 0.18 & 0.32 & 0.59 & 3.95 \\
SB2 & 3 & $0.37 \pm 0.08$ & 0.60 & $0.44 \pm 0.07$ & $4.25 \pm 0.55$ \\
SB3 & 3 & $0.53 \pm 0.15$ & 0.80 & $0.38 \pm 0.13$ & $2.60 \pm 0.23$ \\
CB & 2 & $0.28 \pm 0.01$ & 0.47 & $0.53 \pm 0.03$ & $3.38 \pm 0.21$ \\
WS & 2 & $0.48 \pm 0.08$ & 0.70 & $0.39 \pm 0.07$ & $3.05 \pm 0.30$ \\
\hline
\end{tabular}

Table 3. Similarity matrices of Jaccard and Sorensen-Dice indices between carabid communities in the examined localities. Highest values for both indices are in bold.

\begin{tabular}{|c|c|c|c|c|c|c|c|c|c|c|c|}
\hline \multicolumn{6}{|c|}{ Jaccard Index (JS) } & \multicolumn{6}{|c|}{ Sørensen-Dice Index (DS) } \\
\hline \multicolumn{6}{|c|}{ Locality } & \multicolumn{6}{|c|}{ Locality } \\
\hline & SB1 & SB2 & SB3 & $\mathrm{CB}$ & WS & & SB1 & SB2 & SB3 & $\mathrm{CB}$ & WS \\
\hline SB1 & & & & & & SB1 & & & & & \\
\hline SB2 & 0.34 & & & & & SB2 & 0.51 & & & & \\
\hline SB3 & 0.32 & 0.32 & & & & SB3 & 0.48 & 0.49 & & & \\
\hline $\mathrm{CB}$ & 0.26 & 0.24 & 0.23 & & & CB & 0.41 & 0.39 & 0.38 & & \\
\hline WS & 0.17 & 0.17 & 0.21 & 0.28 & & WS & 0.30 & 0.29 & 0.34 & 0.43 & \\
\hline
\end{tabular}

Variability explained by localities was about four-times higher than that explained by the sampling date (time series A) in the analysis that included all species. However, variability explained by the sampling date increased faster with species elimination, and eventually became half that explained by the localities (Figure 1b). The increase in variability explained by time series A was similar in the $\mathrm{SaS}$ and SaT models. The smallest increase in variability was observed in the TaT model (Figure 1b). Variability explained by years was very low in all models (Figure 1c).

The lowest percentage of variability explained by localities occurred in the TaT model and in the SaS model at the beginning of modeling $(x \leq 150)$, suggesting that these two approaches were most appropriate to compare the least locality-dependent environmental impacts. However, these procedures required the determination of all individuals to the species level, and in the case of the TaT model also their classification into categories of functional traits. Neither of these requirements can be fulfilled in routine practice. However, variability explained by localities in the SaT model was at $x=229$, exceeded by variability explained by the SaS model, and then increased slowly up to $x=600$ (Table 4). Species with abundance lower than 230 (in total for all localities) could be excluded from the analysis, while species with abundance higher than 600 (10 species, 14 categories) had to be included (this range is highlighted in Figure 1) to avoid a high increase of variability. Six species were found in all localities and their total abundance surpassed 600 (Table 5). The SaT model showed conditions that have to be fulfilled for reliable comparison of different localities in routine practice.

Table 4. Changes in the variability explained by environmental variables in the SaS, SaT, and TaT models (see Section 5.3 Data Analysis) in CCA between cut-off levels 230 and 600 individuals per species. Values based on data are given before parentheses and values in parentheses are based on values interpolations from the constructed curves.

\begin{tabular}{cccc}
\hline Environmental Variable & SaS & SaT & TaT \\
\hline Locality & $5.2(12.1)$ & $0.1(6.5)$ & n.a. $^{1}(1.2)$ \\
Time series A (Sampling date) & $2.3(3.6)$ & $0.9(3.1)$ & n.a. $(0.3)$ \\
Year & 0.1 (n. a.) & $0.5(0)$ & n.a. $(0.1)$ \\
\hline \multicolumn{5}{c}{ n.a.: not available. }
\end{tabular}




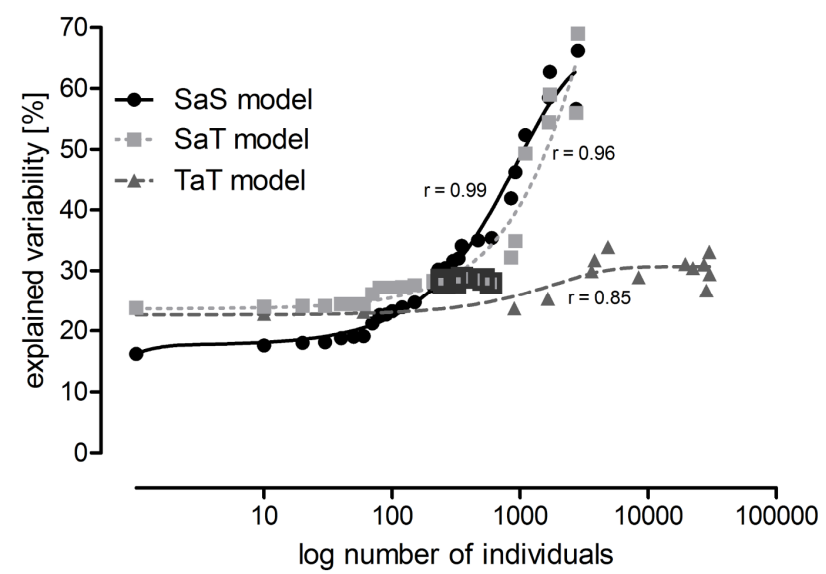

(a)

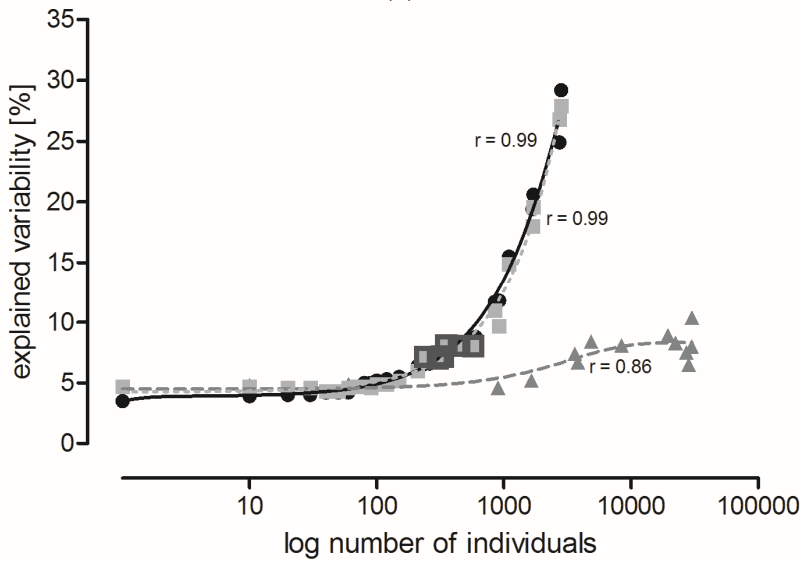

(b)

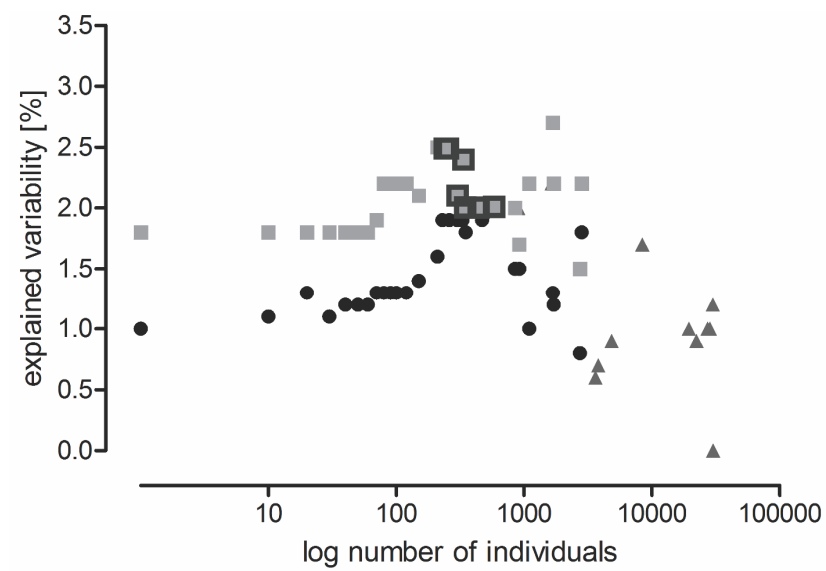

(c)

Figure 1. Variability in the carabid grouping composition explained by: (a) locality; (b) sampling date (time series A); and (c) year in the SaS model (solid lines), SaT model (dotted lines), and TaT model (broken lines). Each point represents a Canonical Correspondence Analysis (CCA). Consecutive points were calculated allowing the same data to be analyzed, but the least abundant species (SaS and SaT models) or categories of functional traits (TaT model) were eliminated, and CCA was performed at the species level (SaS model) or at the level of functional traits (SaT and TaT models). Individuals were gradually eliminated with a cut-off level of 10 . In the SaS and SaT models, species elimination proceeded until the three most common species were left. In the TaT model, the categories of functional traits were eliminated until the three most common categories remained. Highlighted points represent analyses where species with abundance from 230 to 600 individuals are preserved (explained in Section 2.3 Three Possible Ways of Using Carabids in PMEM). 
In the SaT model at a cut-off level of 600 , most of the categories of functional traits were distributed around the center of the ordination diagram; their presence was similar in all localities. However, the incidence of hygrophilous species tended to be higher in WS, and species in body size category C were most common in SB1 (Figure 2). Similar carabid groupings were found in SB1 and SB2, which were about $2-\mathrm{km}$ apart, including $1 \mathrm{~km}$ of a forest. A similar species composition was also found in SB3 (Table 3), but the species abundance was different (Figure 2).

When we compared plots with GM events and plots treated with insecticides at a cut-off level of 600 , the variability explained by these localities was $20.7 \%$. It was lower than baseline (Figure 1a: SaT model, $x$ (no. of individuals) $=600, y$ (explained variability) $=28.1 \%$, indicating low probability of an impact of GM maize on the carabid groupings in these localities (Figure 3a). When GM events were compared with near-isogenic cultivars, variability among these plots in different localities was $28.9 \%$ (Figure $3 b$ ), which is still around the level of variability explained by different localities. A higher difference would indicate that the GM crop had an impact on the agroecosystem.

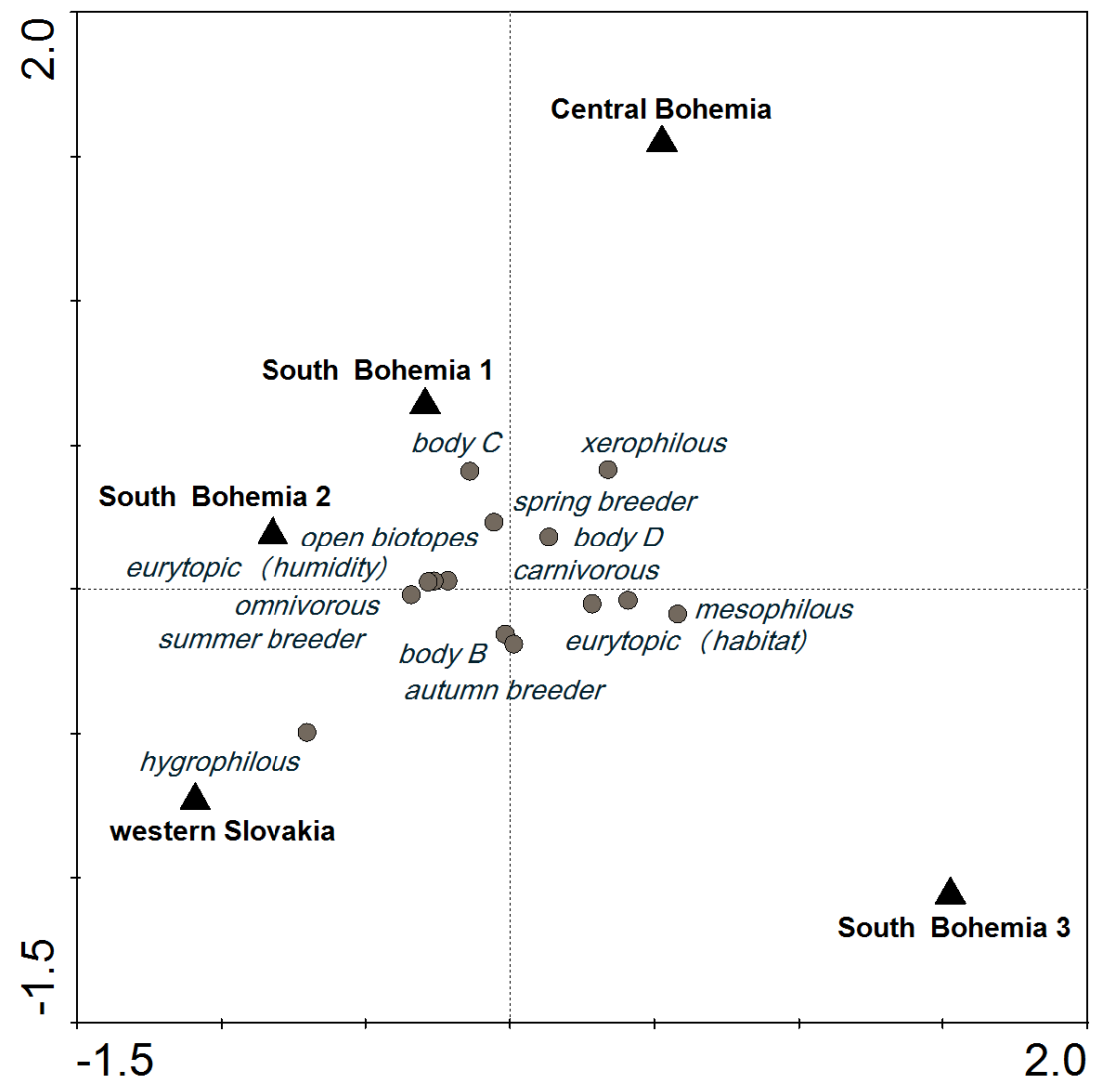

Figure 2. CCA ordination diagram showing the importance of locality for functional trait categories of carabids that reached an abundance of at least 600 (10 species, 14 categories) based on the SaT model (explained in Section 5.3 Data Analysis). 
Table 5. Species with abundance higher than 230 included in the CCA analysis of the SaT model (explained in Section 5.3 Data Analysis) and their functional classification (explained in footnote of Table 1). Species with abundance higher than 600 are highlighted in bold. Underlined species were sampled in all localities.

\begin{tabular}{|c|c|c|c|c|c|c|}
\hline Species & Total Abundance & Body Size & Habitat Affinity & Humidity Affinity & Breeding Period & Food Specialization \\
\hline Agonum muelleri & 256 & $\mathrm{C}$ & Eurytopic & Hygrophilous & Spring & Carnivorous \\
\hline Anchomenus dorsalis & 1099 & $\mathrm{C}$ & Open biotopes & Hygrophilous & Spring & Carnivorous \\
\hline Bembidion lampros & 462 & $\mathrm{D}$ & Open biotopes & Eurytopic & Spring & Carnivorous \\
\hline Bembidion quadrimaculatum & 1680 & $\mathrm{D}$ & Open biotopes & Eurytopic & Spring & Carnivorous \\
\hline Brachinus crepitans & 348 & $\mathrm{C}$ & Open biotopes & Xerophilous & Summer & Carnivorous \\
\hline Brachinus explondes & 294 & $\mathrm{D}$ & Open biotopes & Hygrophilous & Spring & Carnivorous \\
\hline Calathus fuscipes & 2811 & $\mathrm{~B}$ & Open biotopes & Xerophilous & Autumn & Carnivorous \\
\hline$\overline{\text { Carabus granulatus }}$ & 596 & B & Silvicolous & Hygrophilous & Spring & Carnivorous \\
\hline Clivina fossor & 325 & C & Open biotopes & Hygrophilous & Spring & Carnivorous \\
\hline Harpalus affinis & 920 & $\mathrm{C}$ & Open biotopes & Eurytopic & Spring/summer/autumn & Omnivorous \\
\hline Harpalus rubripes & 2734 & $\mathrm{C}$ & Open biotopes & Eurytopic & Spring & Omnivorous \\
\hline Poecilus cupreus & 15,975 & B & Eurytopic & Eurytopic & Spring & Omnivorous \\
\hline Poecilus versicolor & 1710 & $\mathrm{C}$ & Open biotopes & Hygrophilous & Spring & Carnivorous \\
\hline Pseudoophonus rufipes & 7871 & B & Open biotopes & Eurytopic & Autumn & Omnivorous \\
\hline Pterostichus melanarius & 18,297 & B & Eurytopic & Mesophilous & Autumn & Carnivorous \\
\hline$\overline{\text { Trechus quadristriatus }}$ & 841 & $\mathrm{D}$ & Open biotopes & Mesophilous & Autumn & Carnivorous \\
\hline
\end{tabular}




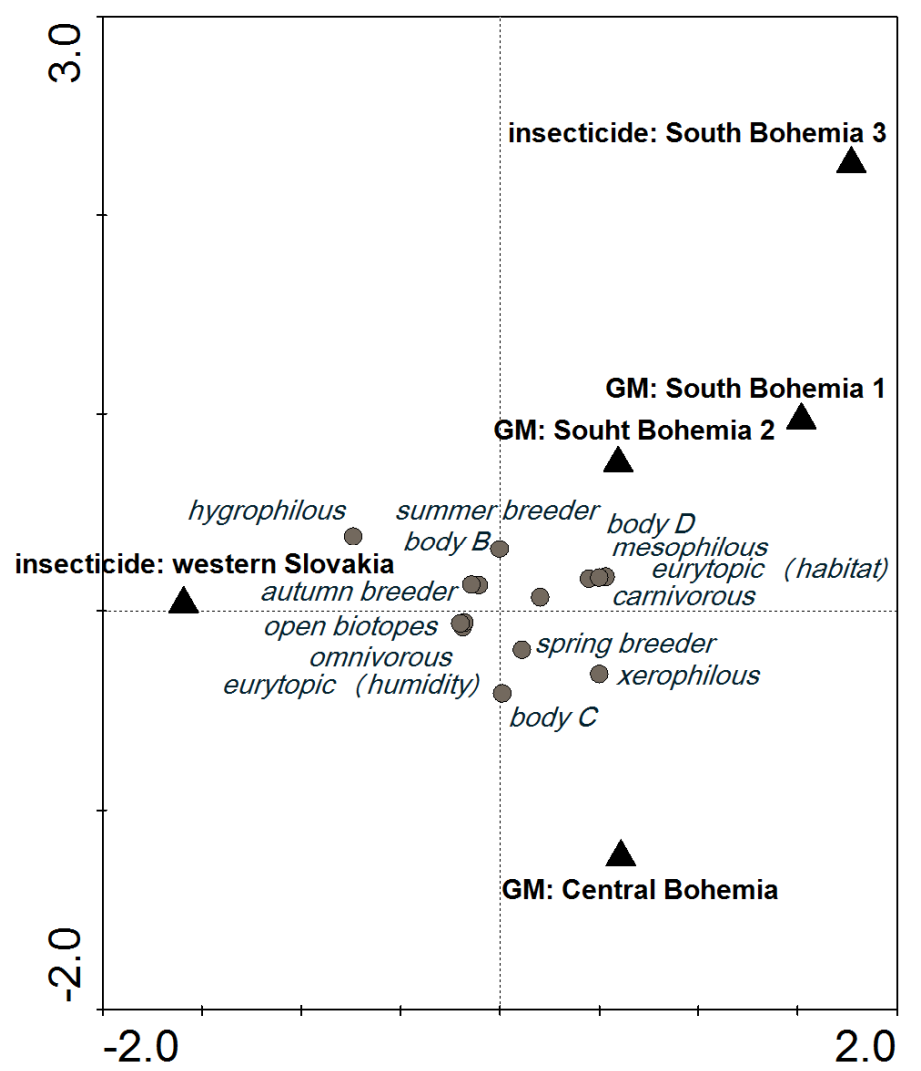

(a)

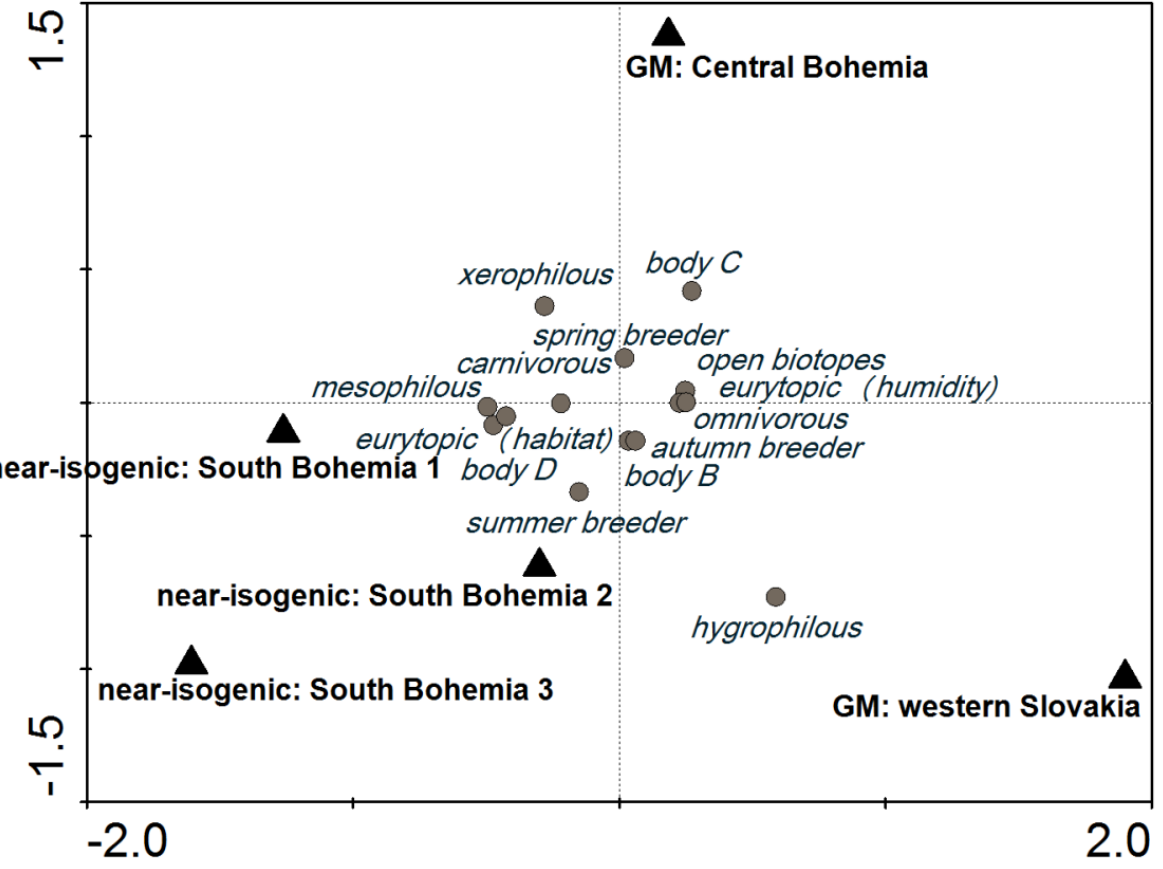

(b)

Figure 3. Comparison of plots with different treatments: (a) plots with GM events (SB1, SB2, and CB) compared with plots treated with insecticide (SB3 and WS) at a cut-off level of 600; and (b) plots with GM events (CB and WS) compared with plots with near-isogenic cultivars (SB1, SB2, and SB3) at a cut-off level of 600. CCA ordination diagrams are based on the SaT model (explained in Section 5.3 Data Analysis). 


\section{Discussion}

Development of a PMEM method that is applicable in a large geographic area at reasonable cost is very challenging. Such a method should be based on indicators that are relatively easy to monitor, occur in vast territories from spring to autumn, and are exposed to the products of transgenes in GM crops. Carabids fulfill these requirements, but the feasibility of their monitoring has not been sufficiently analyzed. Therefore, our study focused on the nature and size of data needed for reliable distinctions between carabid communities in different localities, years, and sampling dates. Carabid assemblages were analyzed in respect to the species composition and functional traits. This approach was preferred over the analysis of total abundance of the carabid family.

\subsection{Carabid Communities in Maize Fields}

To facilitate comparison with other studies, we used several indices to characterize carabid communities in different localities. The values of diversity indices were more or less in the range of those reported across Europe [17,32,36,37]. Similarity indices based on the qualitative species comparison declined with the distance between compared localities. Conversely, functional diversity was similar in remote localities; all important categories of functional traits were present in all localities (TaT model, Figure 1a).

The Berger-Parker index is an effective, simple tool for monitoring impaired biodiversity in soil ecosystems due to human disturbances [38]. Index values increase from undisturbed to disturbed areas. In the present study, values ranging from 0.32 (SB1) to 0.70 (WS) were typical for sites with agricultural management and indicate the prevalence of one species. Use of this index can facilitate interpretation of soil biodiversity patterns in the context of ecosystem management and conservation. The index of species evenness was low. It ranged from 0.38 (SB) to 0.59 (SB1), and reflected dominance by one species and very low abundance of others [39].

The dominance of a few species varied in their dependence on locality, and annual changes in environmental and anthropogenic factors [36,37,39]. The 16 most abundant species in our study are common in the fields of Central Europe [17,34,36,37,39,40], and some are also found in southern Europe [9,11,41], the United Kingdom [32], and Balkan [42]. This suggests similarity in agrocoenoses across a large area; usually 10-20 frequently occurring species rotate in the position of the most abundant species. However, only five of these species (C. fuscipes, H. affinis, P. cupreus, P. melanarius, and T. quadristriatus) were among the 10 most common species in all localities. According to literature sources $[9,11,17,32,34,36,37,39-42]$ and our experience, we suggest that it is appropriate to compare the abundance of a group of 10-20 common species based on their functional classification. A similar conclusion has been reached by other authors [11].

\subsection{Variability Explained by Locality and Environmental Variables}

Site location is by far the most important source of variability [8]. Locality is therefore important for making a baseline between background variability caused by other factors than the studied treatment. Several studies have compared trials conducted under different management regimes and used different statistical methods to define the sample size sufficient to detect impacts of GM crops on the abundance of arthropods [8,9,11,43-45]. We used CCA with three types of gradual species reduction or categories of functional traits to identify the minimum sample size that would sufficiently minimize the locality-dependent variability. Modeling was based on species abundance, and representation of categories of functional traits (explained in Section 5.3 Data Analysis). When all data were included in the analysis (first point in Figure 1a), the percentage of variability explained by localities was lowest in the SaS model, which showed the importance of species of low abundance for the similarity assessments of distant localities. The SaT model showed that variability explained by localities remains relatively low when species with abundance lower than 230 individuals are neglected. Species can be further eliminated from the analysis up to a threshold of 600 individuals per 
species. Exclusion of species with higher abundance causes a very steep increase in variability among localities. We do not recommend analyses based on less than 10 most common species. A trait-based analysis with the most common species is a compromise that can be utilized for large scale PMEM (limitations of PMEM are discussed in [10]). Species with an abundance lower than 230 can be excluded from the analysis, while those with an abundance higher than 600 must be preserved to avoid a high increase of unwanted variability.

We observed baseline background variability for carabid grouping comparisons in five different localities. If the percentages of variability explained by the GM and non-GM treatments were higher than the baseline for these localities, an impact of the GM crop on the agroecosystem may be indicated. The baseline for similar localities is lower than for the less similar localities. Thus, it is necessary to determine the approximate baseline variability for the examined localities.

Maize phenology was not crucial for the carabid grouping (shared variability between time series $\mathrm{S}$ and $\mathrm{A}$ ). We propose to follow a time series based on the calendar date rather than on the date of maize sowing, as this varies between localities and years. The day 1 April seems to be a reliable landmark for Central Europe and probably for most of Europe.

Differences of 14 days between corresponding samplings in different localities were not uncommon in our study. Given the low percentage of variability explained by the sampling date, the precise timing of samplings in different localities is not needed. Our conclusions are mostly based on four samplings per season. Since the abundance and species composition fluctuate during the season [36], a minimum of four samplings per season are required. A reduced sampling number may lead to a considerable loss in the capacity to detect differences [45]. Most studies have confirmed the highest carabid abundance around the time of maize flowering [11,46], although this is not the rule [10]. It is advisable to cover the first part of the season (until grain development, [21]).

Unlike the findings of previous studies [8,11], the effect of different sampling years was relatively low and can be neglected. It seems that direct comparison with a current non-GM crop baseline should be used if available, but reference can also be made to historical baseline data [7].

\subsection{The Applicability of Our Findings for GS in PMEM of GM Maize}

Recommendations based on the findings of our study should be taken into account when designing statistical comparisons in PMEM. If any unintended effect is observed, the recommended data analysis will help to determine whether the adverse effect is associated with the use of a GM crop or whether it is a consequence of other environmental factors [47].

Many authors have highlighted the importance of field size and the availability of non-crop habitats adjacent to the field [36,39]. Those factors should be taken into account when differences among localities are to be interpreted. Multivariate analysis, as used in our study, is a multidimensional tool that considers the effects of many variables, and is appropriate for evaluating and subtracting the effects of these covariables.

Although the European Food Safety Authority (EFSA) claims that GS is not necessarily crop or event specific [4], we are convinced that GS methodology could be the same for different crops, but the direct comparison of carabid assemblage in various crops species, and the effects of agricultural practice are scientifically not defensible because the species and abundance composition is largely affected by crop type even in one locality. This was clearly shown for GM and near-isogenic cultivars of maize, beet, and oil seed rape [32]. 


\section{Conclusions}

The conservation of natural enemies, which as an important component of biological control, can be accepted as the endpoint of PMEM. We propose that these are monitored by analyzing captured carabid species with respect to their abundance and ecological functions. Reliable results are obtained with commonly occurring and abundant species representing important functional categories. Field location is the main factor limiting the detection of changes caused in carabid assemblages by other factors, including the introduction of GM crops. The location effect is preserved at a tolerable level by including only species that occur in relatively high numbers in all examined sites. We demonstrate that, in the case of our model, the inclusion of 10 species, each represented by $\geq 600$ individuals (total count from all sites) is essential, while 70 species with less than 230 individuals each could be excluded without a significant increase in variability observed. The geographically closest localities with similar environmental properties should be preferably compared to reduce differences. At least four samplings during the season are recommended on similar, but not necessarily the same, dates. A time series based on the calendar date can be followed, and data from different years can be combined. Data from independent carabid analyses in maize fields (and possibly in the plantations of some other crops) can be included in future analyses and further increase the precision of PMEM. The proposed method is a compromise that enables the detection of small but meaningful differences at maximally reduced labor costs.

\section{Materials and Methods}

\subsection{Experimental Localities}

Field trials were performed in localities designated as South Bohemia 1, 2, and 3 (SB1, SB2, and SB3); Central Bohemia (CB); and western Slovakia (WS). Basic features of all localities are summarized in Table 6; details on WS site are provided here. Carabid data obtained from the sites SB1, SB2, and CB have been published (see references in Table 6) and are not evaluated from the perspective of the present study.

The WS trial was performed in a field previously planted with winter wheat. In the first trial, three treatments were applied in four replicates (12 plots in total, $30 \times 30 \mathrm{~m}$ each). In the second trial, two treatments were tested in 10 replicates ( 20 plots in total, $10 \times 10 \mathrm{~m}$ each). Each plot was isolated by a 1 - and $5-\mathrm{m}$ wide strip of barley in the first and second trial, respectively. Fertilization with urea $\left(\mathrm{CH}_{4} \mathrm{~N}_{2} \mathrm{O}, 100 \mathrm{~kg} / \mathrm{ha}\right)$ and Polidap $\left(18 \% \mathrm{~N}, 46 \% \mathrm{P}_{2} \mathrm{O}_{5}, 200 \mathrm{~kg} / \mathrm{ha}\right)$ was applied before sowing in 2014, and with urea and NPK 15-15-15 ( $\left[\mathrm{NH}_{4}^{+}, \mathrm{NO}^{-}{ }^{-}, \mathrm{P}_{2} \mathrm{O}_{5}, \mathrm{~K}_{2} \mathrm{O}, 150 \mathrm{~kg} / \mathrm{ha}\right.$ ) in 2015. Trials were treated with the pre-emergent selective herbicide Dual Gold (s-metolachlor, $1.25 \mathrm{~L} / \mathrm{ha}$ ) and Mustang (florasulam, 0.8 L/ha) on 7-26 May 2014, and with Wing (dimethenamid-p, pendimethalin, $4.0 \mathrm{~L} / \mathrm{ha}$ ) on 7 May 2015. All neighboring fields in both years were sown with oilseed rape. Carabid assemblages from the two trials were combined. 
Table 6. Basic features of the examined localities and information on field trials in the localities South Bohemia 1 (SB1), 2 (SB2), and 3 (SB3); Central Bohemia (CB); and western Slovakia (WS)

\begin{tabular}{|c|c|c|c|c|c|}
\hline Features & SB1 & SB2 & SB3 & СВ & WS \\
\hline $\begin{array}{l}\text { Timing (sowing-harvest, } \\
\text { maize stage during harvest) }\end{array}$ & $\begin{array}{l}2002 \\
(15.5-17.9 .(\mathrm{BBCH} 87))\end{array}$ & 2003-2005 & 2009-2011 & 2013-2014 & $\begin{array}{l}\text { 2014-2015 } \\
\text { (2014: 28.4-29.10. } \\
\text { 2015: 5.5-30.10. (2nd trial), } \\
\text { 4.11. (1st trial) (BBCH 89)) }\end{array}$ \\
\hline GPS coordinates & $48^{\circ} 97^{\prime} \mathrm{N} 14^{\circ} 44^{\prime} \mathrm{E}$ & $48^{\circ} 58^{\prime} \mathrm{N} 14^{\circ} 24^{\prime} \mathrm{E}$ & $48^{\circ} 59^{\prime} \mathrm{N} 14^{\circ} 20^{\prime} \mathrm{E}$ & $50^{\circ} 09^{\prime} \mathrm{N} 15^{\circ} 11^{\prime} \mathrm{E}$ & $48^{\circ} 34^{\prime} \mathrm{N} 17^{\circ} 43^{\prime} \mathrm{E}$ \\
\hline Altitude (m a.s.l.) & 381 & 409 & 420 & 285 & 160 \\
\hline Climatic region & $\begin{array}{l}\text { Moderately } \\
\text { warm humid }\end{array}$ & $\begin{array}{l}\text { Moderately } \\
\text { warm humid }\end{array}$ & Moderately warm humid & Warm, slightly dry & Warm, moderate arid \\
\hline Average annual temperature $\left({ }^{\circ} \mathrm{C}\right)$ & 8.1 & 8.1 & 8.1 & 8.9 & 9.2 \\
\hline Average annual precipitation $(\mathrm{mm})$ & 623 & 623 & 623 & 596 & 593 \\
\hline Prevalent soil type & $\begin{array}{l}\text { Cambisol, sandy } \\
\text { loam brown }\end{array}$ & $\begin{array}{l}\text { Cambisol, sandy } \\
\text { loam brown }\end{array}$ & $\begin{array}{l}\text { Medium-weight, mildly humid } \\
\text { clay-loam brown }\end{array}$ & $\begin{array}{l}\text { Medium-grained black } \\
\text { floodplain from debris }\end{array}$ & Loamy luvic chernozem \\
\hline Trial area (ha) & 7.6 & 14 & 15 & 4.38 & 2.9 (1st trial); 0.52 (2nd trial) \\
\hline No. of plots (plot size in ha) & $10(0.5)$ & $10(0.5)$ & $25(0.5)$ & $54(0.054)$ & $12(0.09,1$ st trial $) ; 20(0.01,2$ nd trial $)$ \\
\hline No. of pitfall traps per plot/total amount & $5 / 50$ & $5 / 50$ & $5 / 125$ & $2 / 108$ & $2 / 24$ (1st trial); $2 / 40$ (2nd trial) \\
\hline GM cultivar (No. of plots) & $\begin{array}{l}\text { YieldGard } \\
\text { MON } 810^{1}(5)\end{array}$ & $\begin{array}{l}\text { YieldGard }^{\circledR} \\
\text { MON } 810^{1}(5)\end{array}$ & $\begin{array}{l}\text { YieldGard } \\
\text { VT Rootworm/RR2 }{ }^{\mathrm{TM}} \mathrm{MON} 88017^{1}(5)\end{array}$ & $\begin{array}{l}\text { Roundup Ready } 2 \\
\text { NK } 603^{1}\left(54^{2}\right)\end{array}$ & $\begin{array}{l}\text { YieldGard }^{\circledR} \\
\text { MON } 810^{1} \text { (4 in 1st trial; } \\
10 \text { in } 2 \text { nd trial) }\end{array}$ \\
\hline Near-isogenic cultivar (No. of plots) & Monumental (5) & Monumental (5) & DK $315\left(5,5^{3}\right)$ & None & $\begin{array}{l}\text { DKC } 3871(4,4 \text { in 1st field trial; } \\
\left.10 \text { in } 2 \text { nd field trial }{ }^{4}\right)\end{array}$ \\
\hline Other treatments (No. of plots) & None & None & $\begin{array}{l}\text { (b) Cultivar Kipous (KWS SAAT AG) (5) } \\
\text { (c) Cv. PR38N86 (DuPont Pioneer) (5) }\end{array}$ & None & None \\
\hline References & [48] & {$[10,49]$} & [50] & [46] & None \\
\hline
\end{tabular}

${ }^{1}$ MONSANTO Technology LLC; ${ }^{2}$ Treatments: Herbicides: (a) Foramsulfuron; (b) Glyphosate: split application; and (c) Glyphosate + acetochlor, Tillage: (a) Conventional; (b) Reduced; and (c) Cover crops: Hordeum vulgare, Phacelia tanacetifolia, Sinapis alba or Trifolium incarnatum; ${ }^{3}$ Treatments: (a) DK 315 alone; and (b) DK $315+$ insecticide chlorpyrifos; ${ }^{4}$ Treatments: 1 st trial: (a) DKC 3871 + lambda-cyhalothrin (0.25 L/ha); and (b) DKC 3871 + bioinsecticide Bacillus thuringiensis ssp. kurstaki (1.5 L/ha), 2nd trial: DKC 3871 + lambda-cyhalothrin. 


\subsection{Capture and Identification of Carabids}

Pitfall traps (9-cm diameter, $0.5-1$ volume) were supplied with about $300 \mathrm{~mL} 10 \% \mathrm{NaCl}$ and 2-3 drops of detergent (SB1, SB2, SB3, CB), or with ethylene glycol and water 1:1, (WS), covered with aluminum coping and exposed for 7 days. Different numbers of pitfall traps were used (calculated per ha: seven traps in SB1, four in SB2, eight in SB3, 25 in CB, and 19 in WS; 3669 pitfall trap collections in total).

Samples in SB1, SB2, SB3, and CB were collected at maize stages BBCH 09, BBCH 16, BBCH 65, and $\mathrm{BBCH} 87$ [51]. In WS, samples were collected every other week at maize stages $\mathrm{BBCH} 09, \mathrm{BBCH} 11$, $\mathrm{BBCH} 13, \mathrm{BBCH} 17, \mathrm{BBCH} 34, \mathrm{BBCH} 53, \mathrm{BBCH} 63, \mathrm{BBCH} 69, \mathrm{BBCH} 79$, and $\mathrm{BBCH} 89$ (sampling dates are provided in Table S1, Supplementary Materials).

Carabids were stored in 70\% ethanol and identified to species level [52] (Table S2, Supplementary Materials). Body size, humidity, habitat affinities, breeding period [52], incidence [53,54], and food specialization [23] were determined for each species (Table S3, Supplementary Materials).

\subsection{Data Analysis}

We used the following ecological indices to compare the diversity of carabid communities in different localities: Berger-Parker index, Margalef index, Simpson dominance index, and Species evenness. The Jaccard index and Sørensen-Dice index were applied to assess the similarity of communities in different localities [55].

Carabid distribution was analyzed using multivariate analysis (Canoco software for Windows 4.5, Plant Research International, [56]). The analysis concerned the abundance of species and their placing in the functional trait categories for body size, habitat and humidity affinities, breeding period, and food specialization. The detected gradient length (4.9) in the detrended correspondence analysis (DCA: 0.001 attributed to each value, detrending by segments, $\log$ transformation: $x^{\prime}=\log (x+1)$, downweighting of rare species) of distribution trends and the characterization of data enabled us to use canonical correspondence analysis (CCA: 0.001 attributed to each value, log transformation, Hill's scaling). The effects of geographic localization of each locality (dummy variables), year (dummy variables), and sampling date were tested (environmental variables). A two-time series was used to test the effect of sampling date: (1) time series, S: number of days from the sowing day, marked as number 1; and (2) time series A: number of days from 1 April, which was classed as Day 1 . The day 1 April was selected based on the agro-technical term of maize sowing. The earliest possible term for sowing in Central Europe is around 5 April [57]. The joint explanatory effect of these two variables was assessed by the analysis of variability explained with the time series $\mathrm{S}$ and $\mathrm{A}$ in two separate CCAs, and together in a single CCA (variance partitioning procedure, [56]). The significance of the effects of environmental variables was tested by subtracting the effect of covariables (CCA in partial shape, Monte Carlo permutation tests, MCPT: 999 permutations, unrestricted permutations, forward selection). Covariables are environmental variables whose influence is subtracted before that of variables of interest is investigated [56]. Covariables were those environmental variables mentioned above whose effect were not tested in certain CCAs.

Variability explained by environmental variables in CCA was compared for three different types of gradual elimination of individuals with a cut-off level of 10:

1. SaS model: the least abundant species were eliminated and a CCA was performed at the species level (Table S4);

2. SaT model: the least abundant species were eliminated and a CCA was performed at the level of functional traits (Table S5); and

3. TaT model: the least frequent categories of functional traits were eliminated and a CCA was performed at the level of functional traits (Table S6).

In the SaS and SaT models, species elimination proceeded until three most common species remained. In the TaT model, the categories of functional traits were eliminated until the three most 
common categories remained. Variability explained by models was compared using the curve (two-phase exponential association, coefficient of correlation r, Graph Pad Prism 4.5, [58]). One-way ANOVA (F-tests accompanied by degrees of freedom and degrees of freedom of the error) was applied to compare differences in variability explained during modeling [59].

We defined baseline as a background variability that is caused by other factors (covariables in multivariate analysis) than the variables (GM vs. non-GM) whose effect is important for the purpose of the study. We hypothesize that when we know baseline, it is possible to distinguish between the background variability and variability caused by growing GM maize. The example of separation of effect of baseline from effect of GM maize is presented in Figure 3a,b. The carabid grouping in GM maize is compared there with carabid groupings in plots treated with insecticides (as they are applied in most of maize cropping systems) and plots with near-isogenic cultivar, respectively.

Supplementary Materials: The following are available online at www.mdpi.com/2072-6651/9/4/121/s1, Table S1: The sample dates of deployment of pitfall traps in the locality western Slovakia in 2014 and 2015, Table S2: The abundance of carabids in the examined localities in 2002-2015, Table S3: Incidence and functional traits of carabids captured in localities South Bohemia 1, 2 and 3, Central Bohemia and western Slovakia in 2002-2015, Table S4: Data for analysis of explained variability in SaS model, Table S5: Data for analysis of explained variability in SaT model, Table S6: Data for analysis of explained variability in TaT model.

Acknowledgments: We are grateful to Pietro Brandmayr, Lukáš Spitzer and Aleš Bezděk for their advice and help with carabid functional classification. Thanks also belong to Peter Bokor for his help in designing sampling procedure in WS, Michal Grycz for carabid determination, and Radka Tanzer Fabiánová and Ol'ga Janovičová for their technical assistance. Picture of carabid beetle in Abstract graphic was provided by Jan Šula. We thank the Agriculture Company Dubné a.s., Farm Opolany and Agricultural Cooperative in Borovce for field rent and the land management and Monsanto Europe S.A. for providing GM maize seed. This study was supported by Institute of Entomology CAS [RVO:60077344], project MOBILITY [7AMB14SK096], VEGA [1/0732/14] and CAS [L200961652].

Author Contributions: O.S.H. conceived and designed the experiments in the localities SB1, SB2, SB3 and CB; F.S. designed the experiments in the locality SB1; O.S.H. and Z.S. performed the experiments in the localities SB1, SB2, SB3 and CB; L'.C. conceived, designed and performed experiments in the locality WS; Z.S. analyzed the data; and O.S.H., Z.S. and F.S. wrote the paper. All authors have read and approved the final version of the paper.

Conflicts of Interest: The authors declare no conflict of interest. The founding sponsors had no role in the design of the study; in the collection, analyses, or interpretation of data; in the writing of the manuscript, and in the decision to publish the results.

\section{References}

1. Wolfenbarger, L.L.; Naranjo, S.E.; Lundgren, J.G.; Bitzer, R.J.; Watrud, L.S. Bt crop effects on functional guilds of non-target arthropods: A meta-analysis. PLoS ONE 2008, 3, e2118. [CrossRef] [PubMed]

2. European Commission (EC). Directive 2001/18/EC of the European Parliament and of the Council of 12 March 2001 on the deliberate release into the environment of genetically modified organisms and repealing. Council Directive 90/220/EEC. Off. J. Eur. Communities 2001, L106, 1.

3. European Commission. Council Decision of 3 October 2002 establishing guidance notes supplementing Annex VII to Directive 2001/18/EC or the European Parliament and of the Council on the deliberate release into the environment of genetically modified organisms and repealing. Council Directive 90/220/EEC. Off. J. Eur. Communities 2002, L280, 27.

4. EFSA (European Food Safety Authority) Panel on GMO. Opinion of the Scientific Panel on Genetically Modified Organisms on the Post Market Environmental Monitoring (PMEM) of genetically modified plants. EFSA J. 2006, 319, 1-27.

5. Sanvido, O.; De Schrijver, A.; Devos, Y.; Bartsch, D. Post market environmental monitoring of genetically modified herbicide tolerant crops (Working group report from the 4th International Workshop on PMEM of Genetically Modified Plants, Quedlinburg, Germany 2010). J. Kult. Pflanzen. 2011, 63, 211-216.

6. Sanvido, O.; Widmer, F.; Winzeler, M.; Bigler, F. A conceptual framework for the design of environmental post-market monitoring of genetically modified plants. Environ. Biosaf. Res. 2005, 4, 13-27. [CrossRef]

7. EFSA (European Food Safety Authority) Panel on GMO. Scientific Opinion on guidance on the Post-Market Environmental Monitoring (PMEM) of genetically modified plants. EFSA J. 2011, 9, 2316. 
8. Albajes, R.; Farinós, G.P.; Pérez-Hedo, M.; de la Poza, M.; Lumbierres, B.; Ortego, F.; Pons, X.; Castañera, P. Post-market environmental monitoring of Bt maize in Spain: Non-target effects of varieties derived from the event MON810 on predatory fauna. Spanish J. Agric. Res. 2012, 10, 977-985. [CrossRef]

9. Albajes, R.; Lumbierres, B.; Pons, X.; Comas, J. Representative taxa in field trials for environmental risk assessment of genetically modified maize. Bull. Entomol. Res. 2013, 103, 724-733. [CrossRef] [PubMed]

10. Skoková Habuštová, O.; Svobodová, Z.; Spitzer, L.; Doležal, P.; Hussein, H.M.; Sehnal, F. Communities of ground-dwelling arthropods in conventional and transgenic maize: Background data for the post-market environmental monitoring. J. Appl. Entomol. 2015, 139, 31-45.

11. Lee, M.S.; Albajes, R. Monitoring carabid indicators could reveal environmental impacts of genetically modified maize. Agric. For. Entomol. 2016, 18, 238-249. [CrossRef]

12. Sanvido, O.; Romeis, J.; Bigler, F. An approach for post-market monitoring of potential environmental effects of Bt-maize expressing Cry1Ab on natural enemies. J. Appl. Entomol. 2009, 133, 236-248.

13. Kotze, D.J.; Brandmayr, P.; Casale, A.; Dauffy-Richard, E.; Dekoninck, W.; Koivula, M.J.; Lövei, G.L.; Mossakowski, D.; Noordijk, J.; Paarmann, W.; et al. Forty years of carabid beetle research in Europe-From taxonomy, biology, ecology and population studies to bioindication, habitat assessment and conservation. ZooKeys 2011, 100, 55-148. [CrossRef] [PubMed]

14. Zahradník, J. Brouci; Aventinum: Praha, Czech Republic, 2008; p. 288.

15. Hi̊rka, K. Střevlíkovití, Carabidae 1; Academia: Praha, Czech Republic, 1992; p. 192.

16. Holland, J.M.; Luff, M.L. The effects of agricultural practices on Carabidae in temperate agroecosystems. Integr. Pest Manag. Rev. 2000, 5, 109-129. [CrossRef]

17. Vician, V.; Svitok, M.; Kočík, K.; Stašiov, S. The influence of agricultural management on the structure of ground beetle (Coleoptera: Carabidae) assemblages. Biologia 2015, 70, 240-251. [CrossRef]

18. Jelaska, L.Š.; Blanuš, M.; Durbešić, P.; Jelaskac, S.D. Heavy metal concentrations in ground beetles, leaf litter, and soil of a forest ecosystem. Ecotoxicol. Environ. Saf. 2007, 66, 74-81. [CrossRef] [PubMed]

19. Pizzolotto, R.; Cairns, W.; Barbante, C. Pilot research on testing the reliability of studies on carabid heavy metals contamination. Balt. J. Coleopterol. 2013, 13, 1-13.

20. Romeis, J.; Meissle, M.; Alvarez-Alfageme, F.; Bigler, F.; Bohan, D.A.; Devos, Y.; Malone, L.A.; Pons, X.; Rauschen, S. Potential use of an arthropod database to support the nontarget risk assessment and monitoring of transgenic plants. Transgen. Res. 2014, 23, 995-1013. [CrossRef] [PubMed]

21. Comas, J.; Lumbierres, B.; Comas, C.; Pons, X.; Albajes, R. Optimizing the capacity of field trials to detect the effect of genetically modified maize on non-target organisms through longitudinal sampling. Ann. Appl. Biol. 2015, 166, 183-195. [CrossRef]

22. Zetto Brandmayr, T. Spermophagous (seed-eating) ground beetles: First comparison of the diet and ecology of the harpaline genera Harpalus and Ophonus (Col., Carabidae). In The Role of Ground Beetles in Ecological and Environmental Studies; Stork, N.E., Ed.; Intercept: Andover, UK, 1990; pp. 307-316.

23. Larochelle, A. The food of carabid beetles (Coleoptera: Carabidae, including Cicindelinae). Fabreries 1990, 5 , $1-132$.

24. Talarico, F.; Giglo, A.; Pizzolotto, R.; Brandmayr, P. A synthesis of feeding habits and reproduction rhythm in Italian seed-feeding ground beetles (Coleoptera: Carabidae). Eur. J. Entomol. 2015, 113, 325-336. [CrossRef]

25. Tooley, J.; Brust, G.E. Weed seed predation by carabid beetles. In The Agroecology of Carabid Beetles; Holland, J.M., Ed.; Intercept: Andover, UK, 2015; pp. 215-230.

26. Honěk, A.; Martinková, Z.; Saska, P. Post-dispersal predation of Taraxacum officinale (dandelion) seed. J. Ecol. 2005, 93, 345-352. [CrossRef]

27. Saska, P.; Němeček, J.; Koprdová, S.; Skuhrovec, J.; Káš, M. Weeds determine the composition of carabid assemblage in maize at a fine scale. Sci. Agric. Bohem. 2014, 45, 85-92. [CrossRef]

28. Kromp, B. Carabid beetles in sustainable agriculture: A review on pest control efficacy, cultivation aspects and enhancement. Agric. Ecosyst. Environ. 1999, 74, 187-228. [CrossRef]

29. Peters, R.H. The Ecological Implications of Body Size; Cambridge University Press: Cambridge, UK, 1983 ; p. 329.

30. Sharova, I.C.H. Life Forms of Carabids; Nauka: Moscow, Russia, 1981; p. 359.

31. Riedel, J.; Romeis, J.; Meissle, M. Update and expansion of the database of bio-ecological information on non-target arthropod species established to support the environmental risk assessment of genetically modified crops in the EU. EFSA Support. Publ. 2016. [CrossRef] 
32. Brooks, D.R.; Bohan, D.A.; Champion, G.T.; Haughton, A.J.; Hawes, C.; Heard, M.S.; Clark, J.S.; Dewar, A.M.; Firbank, L.G.; Perryl, J.N.; et al. Responses of invertebrates to contrasting herbicide regimes in genetically modified herbicide-tolerant crops. I. Soil-surface-active invertebrates. Proc. R. Soc. Lond. B Biol. Sci. 2003, $358,1847-1862$.

33. Clough, Y.; Kruess, A.; Tscharntke, T. Organic versus conventional arable farming systems: Functional grouping helps understand staphylinid response. Agric. Ecosyst. Environ. 2007, 118, 285-290. [CrossRef]

34. Grabowski, M.; Bereś, P.K.; Dąbrowski, Z.T. Charakterystyka wybranych gatunków biegaczowatych (Coleoptera: Carabidae) pod katem ich przydatności dla oceny ryzyka i monitoringu uwalniania GMO do środowiska. Prog. Plant Prot. 2010, 50, 1602-1606.

35. James, C. 20th Anniversary 1996 to 2015 of the Global Commercialization of Biotech Crops and Biotech Crop Highlights in 2015; ISAAA Brief No. 51; ISAAA: Ithaca, NY, USA, 2015; Available online: http:/ / www.isaaa. org/resources/publications/briefs/51/ (accessed on 12 February 2016).

36. Mast, B.; Graeff Hönninger, S.; Claupein, W. Evaluation of carabid beetle diversity in different bioenergy cropping systems. Sustain. Agric. Res. 2012, 2, 127-140. [CrossRef]

37. Purchart, L.; Kula, E. Ground beetles (Coleoptera, Carabidae) agrocenoses of spring and winter wheat. Acta Univ. Agric. Silvic. Mendel. Brun. 2005, 53, 125-132. [CrossRef]

38. Tancredi Caruso, T.; Pigino, G.; Bernini, F.; Bargagli, R.; Migliorini, M. The Berger-Parker index as an effective tool for monitoring the biodiversity of disturbed soils: A case study on Mediterranean oribatid (Acari: Oribatida) assemblages. Biodivers. Conserv. 2007, 16, 3277-3285.

39. Irmler, U. The spatial and temporal pattern of carabid beetles on arable fields in northern Germany (Schleswig-Holstein) and their value as ecological indicators. Agric. Ecosyst. Environ. 2003, 98, 141-151. [CrossRef]

40. Porhajašová, J.; Petřvalský, V.; Šustek, Z.; Urminská, J.; Ondrišík, P.; Noskovič, J. Long-termed changes in ground beetle (Coleoptera: Carabidae) assemblages in a field treated by organic fertilizers. Biologia 2008, 63, 1184-1195. [CrossRef]

41. Farinós, G.P.; de la Poza, M.; Hernández-Crespo, P.; Ortego, F.; Castañera, P. Diversity and seasonal phenology of aboveground arthropods in conventional and transgenic maize crops in Central Spain. Biol. Control 2008, 44, 362-371. [CrossRef]

42. Coman, D.; Roșca, I. Structure, dynamics and abundance of carabid species collected in corn fields. Sci. Pap. Ser. A Agron. 2013, 61, 477-479.

43. Meissle, M.; Lang, A. Comparing methods to evaluate the effects of Bt maize and insecticide on spider assemblages. Agric. Ecosyst. Environ. 2005, 107, 359-370. [CrossRef]

44. Comas, J.; Lumbierres, B.; Pons, X.; Albajes, R. Ex-ante determination of the capacity of field tests to detect effects of genetically modified corn on nontarget arthropods. J. Econom. Entomol. 2013, 106, 1659-1668. [CrossRef]

45. Comas, C.; Lumbierres, B.; Pons, X.; Albajes, R. No effects of Bacillus thuringiensis maize on nontarget organisms in the field in southern Europe: A meta-analysis of 26 arthropod taxa. Transgen. Res. 2014, 23, 135-143. [CrossRef] [PubMed]

46. Svobodová, Z.; Skoková Habuštová, O.; Holec, J.; Holec, M.; Boháč, J.; Jursík, M.; Soukup, J.; Sehnal, F. Weeds and epigeic arthropods communities in herbicide-tolerant maize grown under different herbicide and tillage regimes. Agric. Ecosyst. Environ. 2017. under review.

47. Devos, Y.; Aguilera, J.; Diveki, Z.; Gomes, A.; Liu, Y.; Paoletti, C.; du Jardin, P.; Herman, L.; Perry, J.N.; Waigmann, E. EFSA's scientific activities and achievements on the risk assessment of genetically modified organisms (GMOs) during its first decade of existence: Looking back and ahead. Transgen. Res. 2014, 23, 1-25. [CrossRef] [PubMed]

48. Spitzer, L.; Růžička, V.; Hussein, H.; Habuštová, O.; Sehnal, F. Expression of a Bacillus thuringiensis toxin in maize does not affect epigeic communities of carabid beetles and spiders. Acta Phytotech. Zootech. 2004, 7, 110-112.

49. Habuštová, O.; Doležal, P.; Spitzer, L.; Svobodová, Z.; Hussein, H.; Sehnal, F. Impact of Cry1Ab toxin expression on the non-target insects dwelling on maize plants. J. Appl. Entomol. 2014, 138, 164-172. [CrossRef]

50. Svobodová, Z.; Habuštová, O.; Sehnal, F.; Holec, M.; Hussein, H.M. Epigeic spiders are not affected by the genetically modified maize MON 88017. J. App. Entomol. 2013, 137, 56-67. [CrossRef] 
51. Lancashire, P.D.; Bleiholder, H.; Van den Boom, T.; Langelüddecke, P.; Stauss, R.; Weber, E.; Witzen-Berger, A. An uniform decimal code for growth stages of crops and weeds. Ann. Appl. Biol. 1991, 119, 561-601. [CrossRef]

52. Hi̊rka, K. Carabidae of the Czech and Slovak Republics; Kabourek: Zlín, Czech Republic, 1996; p. 565.

53. Veselý, P.; Moravec, P.; Stanovský, J. Carabidae (střevlíkovití). In Červený Seznam Ohrožených Druhů České Republiky; Farkáč, J., Král, D., Škorpík, M., Eds.; AOPK: Praha, Czech Republic, 2005; pp. 406-411.

54. Holecová, M.; Franc, V. Red (Ecosozological) list of beetles (Coleoptera) of Slovakia. In Red List of Plants and Animals of Slovakia. Ochr. Prír. 2001, 20 (Supp.), 111-128.

55. Magurran, A.E. Measuring Biological Diversity; Blackwell Publishing: Oxford, Great Britain, 2004; p. 215.

56. Lepš, J.; Šmilauer, P. Multivariate Analysis of Ecological Data Using CANOCO; Cambridge University Press: Cambridge, UK, 2003; p. 268.

57. Krishna, K.R. Agroecosystems: Soils, Climate, Crops, Nutrient Dynamics and Productivity; CRC Press: Boca Raton, FL, USA, 2013; p. 552.

58. GraphPad Software Inc. GraphPad Prism 5.0 User's Guide; GraphPad Software Inc.: San Diego, CA, USA, 2007; Available online: http://graphpad.com/guides/prism/5/user-guide/prism5help.html (accessed on 13 August 2016).

59. StatSoft Inc. Statistica Electronic Manual; StatSoft Inc.: Tulsa, OK, USA, 2015; Available online: http:/ / documentation.statsoft.com/STATISTICAHelp.aspx?path=common / AboutSTATISTICA/ ElectronicManualIndex (accessed on 13 August 2016).

(C) 2017 by the authors. Licensee MDPI, Basel, Switzerland. This article is an open access article distributed under the terms and conditions of the Creative Commons Attribution (CC BY) license (http:/ / creativecommons.org/licenses/by/4.0/). 